\title{
Optimaal voorspellen door combineren
}

\section{Inleiding}

Het verkrijgen van nauwkeurig inzicht met betrekking tot de onzekere toekomst is in velerlei opzicht van belang. Het is dan ook niet verwonderlijk dat men streeft naar methoden om nauwkeurige voorspellingen te berekenen. Echter, de onzekerheid in de toekomst maakt dat voorspellingen meer of minder onnauwkeurig zullen zijn. Bij het zoeken naar nauwkeurige voorspelmethoden heeft de nadruk voornamelijk gelegen op het vergelijken van de realisatie met voorspellingen verkregen door verschillende methoden. De nauwkeurigste methode wordt gekozen om voorspellingen te berekenen. Door het volgen van deze analyselijn heeft men relatief weinig aandacht besteed aan het combineren van meerdere voorspellingen tot een nieuwe voorspelling. Deze nieuwe voorspelling zal in het algemeen nauwkeuriger zijn dan de voorspellingen waaruit zij is samengesteld. De verbetering van de voorspelkwaliteit hangt echter af van de nauwkeurigheid van de oorspronkelijke voorspellingen en de mate waarin deze voorspellingen samenhangen. De vraag doet zich dan voor of het combineren van voorspellingen wenselijk is in empirische situaties. Aan de hand van voorspellingen voor omzet en nettowinst van Nederlandse ondernemingen gaan we na in hoeverre de voorspelkwaliteit valt te verbeteren door voorspellingen van managers en analisten te combineren.

Het resterende deel van dit artikel is opgebouwd uit een viertal paragrafen en een appendix. In paragraaf twee gaan we kort in op enige recente Nederlandstalige literatuur met betrekking tot het voorspellen op bedrijfseconomisch terrein. Daarnaast wijzen we op enige Engelstalige publicaties, waaruit de conclusie getrokken kan worden dat voorspellen door combineren zinvol is. Vervolgens laten we in de derde paragraaf zien hoe twee voorspellingen optimaal tot een nieuwe voorspelling kunnen worden gecombineerd, waarbij we tevens aangeven in welke mate de voorspelkwaliteit toeneemt. De geschetste methode is nauw verwant aan de efficiënte portefeuille-theorie. In de vierde paragraaf bespreken we in hoeverre het combineren van management-, analisten- en tijdreeksvoorspellingen van omzet en nettowinst leidt tot een verbetering van de voorspelkwaliteit. Dit aspect is met name van belang in verband met de discussie rond de verplichte publicatie van prognostische informatie door ondernemingen. Daarnaast wordt in deze paragraaf ook aandacht besteed aan de samenhang tussen 
voorspellingen, zodat valt na te gaan op welke wijze managers en analisten tijdreeksinformatie verwerken in hun prognoses. De laatste paragraaf besluit met een samenvatting van de belangrijkste resultaten. In de meer technisch georiënteerde appendix bespreken we hoe meer dan twee voorspellingen kunnen worden gecombineerd. Verder wordt in deze appendix ook uiteengezet hoe de relatieve nauwkeurigheid van en de samenhang tussen verschillende voorspellingen valt te bepalen. Voor het volgen van de tekst is het echter niet noodzakelijk om deze appendix te raadplegen.

\section{Kort literatuuroverzicht}

Vanuit de bedrijfseconomie is onlangs in Nederland weer uiting gegeven aan de belangstelling voor de prognoseproblematiek. We noemen het 'Planning and Forecasting'-nummer van het Maandblad voor Accountancy en Bedrijfshuishoudkunde (juni-juli 1982) en de recent verschenen boeken van Van der Meer (1981) en Schreuder en Klaassen (1982a). Van der Meer (1981) heeft onder andere nagegaan in hoeverre jaarverslagen kwalitatieve prognoses bevatten. Daarnaast heeft hij geanalyseerd in welke mate deze kwalitatieve prognoses de richting van de winst juist hebben geindiceerd. Schreuder en Klaassen (1982a) analyseren de betrouwbaarheid van management-, analisten- en tijdreeksvoorspellingen. Daarnaast gaan zij aan de hand van voorspellingsintervallen na in welke mate de inherent aan voorspellen verbonden onzekerheid correct wordt ingeschat. In paragraaf vier gebruiken we het datamateriaal van Schreuder en Klaassen (1982a) om te analyseren in hoeverre het combineren van voorspellingen in deze empirische situatie aanleiding geeft tot een verbetering van de voorspelkwaliteit. Voor het combineren van voorspellingen is het noodzakelijk om over meerdere prognoses te beschikken. Overzichten van diverse voorspelmethoden worden onder andere gepresenteerd in Van Doorn en Van Vught (1982, p. 260), Leeflang (1982, p. 100) en Schreuder en Klaassen (1982a, hfdst. 5). Het streven naar nauwkeurige voorspellingen kan op bedrijfseconomische wijze worden benaderd door de verwachte baten van een nauwkeuriger prognose te vergelijken met de bijbehorende kostenstijging. Van Doorn en Van Vught presenteren een kostenoverzicht van verschillende voorspeltechnieken.

In een kosten-batenanalyse is het mogelijk dat econometrisch meer geavanceerde voorspeltechnieken, zoals gebruikt in Kodde en Palm (1982), niet altijd worden gekozen. De marginale kosten van het combineren van voorspellingen zijn echter gering. Het al dan niet combineren van voorspellingen zal afhangen van de baten verkregen door een hogere voorspelkwaliteit.

Empirische resultaten van Ruland (1978) wijzen indirect op het verbeteren van voorspellingen door combineren. Uit zijn onderzoek blijkt, dat analisten die hun voorspelling publiceren voordat de managementprognose bekend is iets slechter voorspellen, maar dat analisten die na de managementsprognose voorspellen wel iets nauwkeuriger zijn. De verschillen in voorspelkwaliteit zijn echter geenszins significant. De resultaten van Ruland (1978) blijken niet op zich te staan. Zij worden namelijk bevestigd door soortgelijke 
resultaten in Jaggi (1980). Granger en Newbold (1977) vinden direct bewijs voor het verbeteren van voorspellingen door combineren. $\mathrm{Zij}$ vergelijken echter geen management- en analistenvoorspellingen, maar voeren hun analyses uit met verschillende tijdreeksvoorspellingen.

\section{Het combineren van voorspellingen}

Het door ons te presenteren combineren van voorspellingen sluit aan bij de analyses van Bates en Granger (1969) en Granger en Newbold (1977). In deze paragraaf geven we aan hoe twee voorspellingen tot een nieuwe voorspelling kunnen worden gecombineerd. Het combineren van meerdere voorspellingen wordt behandeld in de appendix. Stel we beschikken over twee voorspellingen, $f_{1}$ en $f_{2}$.

We beperken ons hierbij tot voorspellingen die niet systematisch te hoog of te laag voorspellen. In statistische termen wil dit zeggen dat de verwachte voorspelfout gelijk is aan nul. De verwachte kwadratische voorspelfout van beide voorspellingen wordt respectievelijk gegeven door $\sigma_{1}{ }^{2}$ en $\sigma_{2}^{2}$, deze termen zijn equivalent met de variantie van de voorspelfout. Doordat beide voorspellingen deels gebaseerd zijn op dezelfde ontwikkelingen, of mogelijk door overleg tot stand zijn gekomen, bestaat de mogelijkheid dat de voorspellingen met elkaar samenhangen. Deze samenhang wordt aangegeven met $\sigma_{12}$ en is gelijk aan $\rho \sigma_{1} \sigma_{2}$, waarbij $\rho$ de correlatiecoëfficiënt voorstelt. (In statistische termen is $\sigma_{12}$ de covariantie tussen de voorspelfouten.) We bepalen een gecombineerde voorspelling door de twee eerdere voorspellingen $f_{1}$ en $f_{2}$ te wegen met $\lambda$ en $1-\lambda$, zodat de gecombineerde voorspelling gegeven wordt door $f_{c}=\lambda f_{1}+(1-\lambda) f_{2}$. Kiezen we bijvoorbeeld $\lambda=1 / 2$ dan wegen beide voorspellingen even zwaar. Ook voor de gecombineerde voorspelling geldt dat de verwachting van de voorspelfout gelijk is aan nul, terwijl de verwachte kwadratische voorspelfout wordt gegeven door

$\lambda^{2} \sigma_{1}^{2}+2 \lambda(1-\lambda) \rho \sigma_{1} \sigma_{2}+(1-\lambda)^{2} \sigma_{2}^{2}$.

Om nu een optimale voorspelling te verkrijgen moet het gewicht $\lambda$ zodanig worden gekozen dat de uitdrukking in formule (1) minimaal is. Hieruit volgt dat het gewicht voor een optimale voorspelling gelijk gesteld moet worden aan

$\lambda=\left[\sigma_{2}^{2}-\rho \sigma_{1} \sigma_{2}\right] /\left[\sigma_{1}^{2}-2 \rho \sigma_{1} \sigma_{2}+\sigma_{2}^{2}\right]$,

hetgeen volgt door (1) te differentiëren naar $\lambda$ en gelijk te stellen aan nul. We kunnen de minimaal haalbare verwachte kwadratische voorspelfout vinden door het gewicht $\lambda$ bepaald in (2) in te vullen in (1), zodat de minimale kwadratische voorspelfout gegeven wordt door

$\sigma_{\text {min }}^{2}=\left[\left(1-\rho^{2}\right) \sigma_{1}{ }^{2} \sigma_{2}{ }^{2}\right] /\left[\sigma_{1}{ }^{2}-2 \rho \sigma_{1} \sigma_{2}+\sigma_{2}{ }^{2}\right]$.

Als we veronderstellen dat de voorspelkwaliteit van de eerste voorspelling groter of gelijk is dan die van de tweede, d.w.z. $\sigma_{1}{ }^{2} \leqslant \sigma_{2}{ }^{2}$, dan wordt de 
verbetering van de voorspelnauwkeurigheid door te werken met een gecombineerde voorspelling gegeven door $\sigma^{2}{ }_{\min } / \sigma_{1}{ }^{2}$. In tabel 1 geven we de verbetering van de voorspelkwaliteit als functie van de verhouding van de voorspelkwaliteiten van $\mathrm{f}_{1}$ en $\mathrm{f}_{2}$, dit is $\sigma_{2}{ }^{2} / \sigma_{1}{ }^{2}$, en de correlatie.

Aan de hand van enkele numerieke voorbeelden zullen we bovenstaande formules en tabel 1 illustreren. We nemen aan dat de verwachte kwadratische voorspelfout van het management en een financiële analist respectievelijk gelijk zijn aan 1 en 2 . Hetgeen impliceert dat de verwachte absolute voorspelfout van de analist $14 \%$ bedraagt als de verwachte absolute voorspelfout van het management gelijk is aan $10 \%$ (nl. $\sqrt{ } 1 / 2 * 14 \%)$. We zullen voor drie waarden van $\rho$ aangeven wat de voorspelnauwkeurigheid wordt door te combineren, nl. $\rho$ is $-0.7,0.0$ en 0.5 , waarbij we opmerken dat een negatieve correlatie niet waarschijnlijk is in reële situaties. Voor deze voorbeelden krijgen we een optimale voorspelling indien we respectievelijk de volgende gewichten aan de managementvoorspelling toekennen: 0.6, 0.67 en 0.82 , zodat we de analistenvoorspelling respectievelijk moeten wegen met een factor $0.4,0.33$ en 0.18 . Deze gewichten zijn berekend met formule (2). Uit tabel 1 kan afgelezen worden dat de verwachte kwadratische voorspelfout van de gecombineerde voorspelling gemeten ten opzichte van $\sigma_{1}{ }^{2}$ respectievelijk gelijk is aan $0.2,0.67$ en 0.95 .

$\mathrm{Bij}$ de reeds gepresenteerde verwachte absolute voorspelfout van $10 \%$ en $14 \%$ voor management en analist bedraagt de verwachte absolute voorspelfout van de gecombineerde voorspelling bij een correlatie van $-0.7,0.0$ en 0.5 , respectievelijk $4.5 \%$ (nl. $\sqrt{ } 0.2 * 10 \%$ ), $8.2 \%$ en $9.75 \%$, zodat de grootste winst in voorspelkwaliteit kan worden bereikt bij lage correlaties. We besluiten deze paragraaf met een drietal opmerkingen. Ten eerste merken we op dat de voorspelkwaliteit van een gecombineerde voorspelling slechts te verbeteren is indien $\rho \sigma_{2} / \sigma_{1}$ niet gelijk is aan 1 . Dit aspect is zichtbaar in tabel 1.

In de tweede plaats ligt het voor de hand om de voorspelkwaliteit steeds verder te verbeteren door iedere keer een nieuwe voorspelling te berekenen op basis van de vorige gecombineerde voorspelling en zeg $f_{1}$. Deze gedachte is echter niet correct, omdat in deze situatie $\rho \sigma_{2} / \sigma_{1}=1$, zodat hier de eerste opmerking geldt. In de appendix wordt dit punt formeel voor de algemene situatie aangetoond.

Tenslotte geven we aan hoe het combineren van voorspellingen gerelateerd is aan portfolio-analyse. Hiertoe veronderstellen we dat een belegger zijn budget moet verdelen tussen een tweetal beleggingsobjecten met gelijke rendementsverwachtingen, maar niet noodzakelijk met gelijke risico's. Deze belegger verkrijgt een Markowitz-efficiënte portefeuille, d.w.z. in dit geval een portefeuille met minimaal risico bij een gegeven rendement, door zijn budget op grond van formule (2) te verdelen over de beleggingsobjecten. Het risico van deze portefeuille is dan gelijk aan $\sigma^{2}{ }_{\min }$ in formule (3). 
Tabel 1. Realiseerbare verbetering van de voorspelkwaliteit door combineren $\left(\sigma^{2}{ }_{\min } / \sigma_{1}{ }^{2}\right)$

\begin{tabular}{|c|c|c|c|c|c|c|c|c|c|c|c|c|c|c|c|c|c|c|}
\hline \multirow{2}{*}{$\begin{array}{l}\text { corre- } \\
\text { latie } \\
\rho\end{array}$} & \multicolumn{7}{|c|}{ verhouding voorspelkwaliteit van $f_{1}$ en $f_{2}$} & \multicolumn{3}{|c|}{$\sigma_{2}^{2} / \sigma_{1}^{2}$} & \multirow[b]{2}{*}{1.70} & \multirow[b]{2}{*}{1.80} & \multirow[b]{2}{*}{1.90} & \multirow[b]{2}{*}{2.00} & \multirow[b]{2}{*}{2.25} & \multirow[b]{2}{*}{2.50} & \multirow[b]{2}{*}{2.75} & \multirow[b]{2}{*}{3.00} \\
\hline & 1.00 & 1.05 & 1.10 & 1.15 & 1.20 & 1.25 & 1.30 & 1.40 & 1.50 & 1.60 & & & & & & & & \\
\hline-.9 & 0.05 & 0.05 & 0.0 & 0.05 & 0.05 & 0.06 & 0.06 & 0.06 & 0.06 & 0.06 & 0 & 0.07 & 0.07 & 0.07 & .07 & 7 & 0.08 & 0.08 \\
\hline-.8 & 0.10 & 0.10 & 0.10 & 0.11 & 0.11 & 0.11 & 0.11 & 0.12 & 0.12 & 0.12 & 0.13 & 0.13 & 0.13 & 0.14 & 0.14 & 0.15 & 0.15 & 0.16 \\
\hline-.7 & 0.15 & 0.15 & 0.16 & 0.16 & 0.16 & 0.17 & 0.17 & 0.18 & 0.18 & 0.19 & 0.19 & 0.20 & 0.20 & 0.20 & 0.21 & 0.22 & 0.23 & 0.24 \\
\hline-.6 & 0.20 & 0.20 & 0.21 & 0.21 & 0.22 & 0.22 & 0.23 & 0.23 & 0.24 & 0.25 & 0.26 & 0.26 & 0.27 & 0.27 & 0.29 & 0.30 & .31 & .32 \\
\hline-.5 & 0.25 & 0.26 & 0.26 & 0.27 & 0.27 & 0.28 & 0.28 & 0.29 & 0.30 & 0.31 & 0.32 & 0.33 & 0.33 & 0.34 & 0.36 & 37 & 8 & .39 \\
\hline-.4 & 0.30 & 0.31 & 0.31 & 0.32 & 0.33 & 0.33 & 0.34 & 0.35 & 0.36 & 0.37 & 0.38 & 0.39 & 0.40 & 0.41 & 0.42 & 0.44 & 0.46 & 0.47 \\
\hline-.3 & 0.35 & 0.36 & 0.37 & 0.37 & 0.38 & 0.39 & 0.40 & 0.41 & 0.42 & 0.43 & 0.44 & 0.45 & 0.46 & 0.47 & 0.49 & 0.51 & 0.53 & 0.54 \\
\hline-.2 & 0.40 & 0.41 & 0.42 & 0.43 & 0.44 & 0.44 & 0.45 & 0.47 & 0.48 & 0.49 & 0.51 & 0.52 & 0.53 & 0.54 & 0.56 & 0.58 & 0.60 & 0.61 \\
\hline-.1 & 0.45 & 0. & 0.47 & 0.48 & 0.49 & 0 & 0.51 & 0.53 & 0.54 & 0.56 & 0 & 0.58 & 0. & 0.60 & 0.63 & 0.65 & 7 & 0.68 \\
\hline 0.0 & 0.50 & 0.51 & 0.52 & 0.5 & 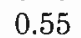 & 0.5 & 0.57 & 0.58 & 0.60 & 0.62 & 0.63 & 0.64 & 0.66 & 0.67 & 0.69 & 0.71 & 0.73 & 0.75 \\
\hline 0.1 & 0.55 & 0.56 & 0.58 & 0.59 & 0.60 & 0.61 & 0.62 & 0.64 & 0.66 & 0.67 & 0.69 & 0.70 & 0.72 & 0.73 & 0.76 & 0.78 & 0.80 & 0.81 \\
\hline 0.2 & 0.60 & 0.61 & 0.63 & 0.64 & 0.65 & 0.67 & 0.68 & 0.70 & 0.72 & 0.73 & 0.75 & 0.76 & 0.78 & 0.79 & 0.82 & 0.84 & 0.86 & 0.87 \\
\hline 0.3 & 0.65 & 0.67 & 0.68 & 0.69 & 0.71 & 0.72 & 0.73 & 0.75 & 0.77 & 0.79 & 0.81 & 0.82 & 0.83 & 0.85 & 0.87 & 0.89 & 0.91 & 0.92 \\
\hline 0.4 & 0.70 & 0.72 & 0.73 & 0.7 & 0.76 & 0.77 & 0.79 & 0.81 & 0.83 & 0.85 & 0.86 & 0.88 & 0.89 & 0.90 & 0.92 & 0.94 & 0.95 & 0.96 \\
\hline 0.5 & 0.75 & 0.77 & 0.78 & 0.8 & 0.8 & 0 & 0.84 & 0.86 & 0.88 & 0.90 & 0.91 & 0.93 & 0.94 & 0.95 & 0.96 & 0.98 & 0.99 & 0.99 \\
\hline 0.6 & 0.80 & 0.82 & 0.84 & 0.85 & 0.87 & 0.8 & 0.89 & 0.91 & 0.93 & 0.8 & 0.96 & 0.97 & 0.98 & 0.98 & 0.99 & 1.00 & 1.00 & 1.00 \\
\hline 0.7 & 0.85 & 0.87 & 0.89 & 0.90 & 0.92 & 0.93 & 0.94 & 0.96 & 0.97 & 0.98 & 0.99 & 1.00 & 1.00 & 1.00 & 1.00 & 0.99 & 0.98 & 0.97 \\
\hline 0.8 & 0.90 & 0.92 & 0.94 & 0.95 & 0.97 & 0.98 & 0.98 & 0.99 & 1.00 & 1.00 & 1.00 & 0.99 & 0.98 & 0.98 & 0.95 & 0.93 & 0.90 & 0.88 \\
\hline 0.9 & 0.95 & 0.97 & 0.99 & 0.99 & 1.00 & 1.00 & 1.00 & 0.98 & 0.96 & 0.94 & 0.91 & 0.89 & 0.86 & 0.84 & 0.78 & 0.73 & 0.68 & 0.65 \\
\hline
\end{tabular}




\section{Voorspellen van omzet en nettowinst}

Uit de vorige paragraaf blijkt dat de voorspelkwaliteit van een gecombineerde voorspelling afhankelijk is van de nauwkeurigheid en de samenhang van de originele voorspellingen. In deze paragraaf gaan we na in hoeverre management- en analistenvoorspellingen door combineren kunnen worden verbeterd. Deze paragraaf bestaat uit vier onderdelen. In de eerste subparagraaf geven we aan op welke wijze de management- en analistenvoorspellingen van omzet en nettowinst zijn verkregen. De grootte van de ondernemingen in het onderzoek is zeer gevarieerd, hierdoor is de samenhang en nauwkeurigheid van de voorspellingen niet zondermeer te bepalen. In de tweede subparagraaf geven we aan hoe deze grootheden wel geschat kunnen worden. Vervolgens laten we in de derde en vierde subparagraaf zien welke verbetering kan worden bereikt door het combineren van omzeten winstvoorspellingen.

\subsection{De omzet- en nettowinstvoorspellingen}

Door het Economisch en Sociaal Instituut van de Vrije Universiteit is een onderzoek uitgevoerd naar de voorspelbaarheid van omzetten en winsten. In het kader van dit onderzoek is eind 1979 aan management en financiële analisten gevraagd om de omzetten en winsten voor 1980 te voorspellen. Uiteindelijk konden we hierdoor voor 34 ondernemingen over zowel een management- als een analistenvoorspelling van de omzet beschikken. Voor de nettowinst waren dat 38 verschillende ondernemingen. Naast de management- en analistenvoorspellingen zijn voor de genoemde grootheden ook voorspellingen met behulp van tijdreekstechnieken berekend. Voor de omzet blijkt dat goede voorspellingen worden verkregen met het random walk met driftmodel, het model geformuleerd in identieke veranderingen en het Elton \& Gruber-model. De winsten worden goed met het random walkmodel voorspeld. Het totale onderzoek, waaronder begrepen onderzoeksopzet, resultaten en evaluatie, wordt uitgebreid besproken in Schreuder en Klaassen (1982a). De belangrijkste aspecten van de management- en analistenvoorspellingen worden ook in Schreuder en Klaassen (1982b) aan de orde gesteld. Kodde en Schreuder (1983) rapporteren over de voorspelkwaliteit van de tijdreekstechnieken en de vergelijking daarvan met management en analisten. Vanwege het bestaan van bovengenoemde publicaties gaan we in dit artikel niet in op deze resultaten. We vatten slechts enkele resultaten kort samen. Het management voorspelt de omzet nauwkeuriger dan de analisten. Het verschil in voorspelkwaliteit is echter niet significant. Voorspellingen van de omzet verkregen door het random walk met driftmodel zijn significant nauwkeuriger dan die van het management en analisten. Voor de winst zijn geen significante verschillen in voorspelkwaliteit te signaleren. De conclusies van het onderzoek worden uitgebreider gepresenteerd in Schreuder en Klaassen (1982a, p. 152 e.v.).

\subsection{Schatten van samenhang en nauwkeurigheid}

We beschikken voor de omzet en de winst over voorspellingen en de realisatie. Op basis van deze gegevens kunnen we de correlatie en de verhouding van de voorspelfoutvariantie schatten. Vanwege de verschillen in 
grootte van de diverse ondernemingen zijn deze grootheden niet nauwkeurig direct te bepalen. Daarom gebruiken we een methode die niet gevoelig is voor de verschillen in grootte. De methode wordt in de appendix mathematisch onderbouwd. We presenteren de methode aan de hand van de winstvoorspellingen. Van de 38 winstvoorspellingen was de prognose van het management in 20 gevallen nauwkeuriger. De analisten voorspelden in 18 gevallen nauwkeuriger. De fractie dat de voorspelfout van het management kleiner is dan die van de analisten bedraagt derhalve 0.526 (dit is 20/38). Voor 7 van de 38 voorspellingen voorspelde de ene groep te hoog terwijl de andere groep te laag voorspelde, zodat de fractie tegengestelde voorspelfouten gelijk is aan 0.184 (nl. 7/38). Door het gebruik van deze fractie en tabel 2 vinden we een geschatte correlatie van 0.85 . We kunnen nu in tabel 3 de verhouding van de verwachte kwadratische voorspelfouten vinden door in de rij die behoort bij een correlatie van 0.85 te kijken naar de waarde die het dichtst in de buurt van $0.526 \mathrm{komt}$. We vinden dan aan de bovenkant van de bijbehorende kolom een waarde van 1.1 voor de verhouding van de verwachte kwadratische voorspelfout. We zijn nu voldoende uitgerust om de mogelijke verbetering van de voorspelkwaliteit voor deze empirische situatie te berekenen.

\subsection{Optimale omzetvoorspellingen}

Zoals in paragraaf 4.1 aangegeven beschikken we voor 34 ondernemingen over een omzetvoorspelling van zowel management als analisten. Daarnaast hebben we voor deze ondernemingen ook voorspellingen berekend met een tweetal tijdreeksmodellen. Ons eerste model, geformuleerd in identieke veranderingen extrapoleert de groei uit het afgelopen jaar. Het tweede model betreft het Elton \& Gruber-model (1972), formeel heet dit model 'exponentially weighted moving average with no trend in trend'. Het model is gebaseerd op de ontwikkelingen in zowel het niveau als in de trend. De mathematische formules van de modellen worden gepresenteerd in Schreuder en Klaassen (1982a, p. 93 e.v.).

Voor deze 34 ondernemingen kunnen we de volgorde van de voorspelnauwkeurigheid bepalen. Het management voorspelde het nauwkeurigst, in afnemende mate van nauwkeurigheid gevolgd door het Elton \& Gruber model, het model in identieke verandering en de analisten. In tabel 4 presenteren we in de eerste twee blokken de fracties tegengestelde voorspelfouten en de fracties kleinere voorspelfouten. Op basis van de methoden uiteengezet in paragraaf 4.2 berekenen we dan schattingen van de correlatie en de verhouding van de verwachte kwadratische voorspelfout. Deze worden respectievelijk in het derde en vierde blok van tabel 4 gegeven.

De fractie tegengestelde voorspelfouten van management ten opzichte van analisten bedraagt 0.242 , waaruit we op basis van tabel 2 een correlatie van 0.70 afleiden. Deze correlatie levert met behulp van tabel 3 en de fractie kleinere voorspelfouten van 0.594 een geschatte verhouding van de verwachte kwadratische voorspelfout van 1.5 . Om een optimale voorspelling van de omzet te vinden substitueren we de geschatte correlatie en variantieverhouding in formule (2). We moeten de managementvoorspelling dan een gewicht geven van 0.82 , zodat de analistenvoorspelling slechts met een 
Tabel 2. Relatie tussen correlatie en fractie tegengestelde voorspelfouten.

fractie te-

$\begin{array}{lllllllllllllllllllll}\text { gengestelde } & 0.50 & 0.48 & 0.47 & 0.45 & 0.44 & 0.42 & 0.40 & 0.39 & 0.37 & 0.35 & 0.33 & 0.31 & 0.30 & 0.27 & 0.25 & 0.23 & 0.20 & 0.18 & 0.14 & 0.10\end{array}$ voorspel

fouten

\begin{tabular}{lllllllllllllllllllll}
\hline correlatie & 0.00 & 0.05 & 0.10 & 0.15 & 0.20 & 0.25 & 0.30 & 0.35 & 0.40 & 0.45 & 0.50 & 0.55 & 0.60 & 0.65 & 0.70 & 0.75 & 0.80 & 0.85 & 0.90 & 0.95 \\
\hline
\end{tabular}

Tabel 3. De fractie kleinere voorspelfout in relatie tot correlatie en verhouding verwachte kwadratische voorspelfout.

\begin{tabular}{|c|c|c|c|c|c|c|c|c|c|c|c|c|c|c|c|c|c|c|}
\hline atie & 1.00 & 1.05 & 1.10 & 1.15 & 1.20 & 1.25 & 1.30 & 1.40 & 1.50 & 1.60 & 1.70 & 1.80 & 1.90 & 2.00 & 2.25 & 2.50 & 2.75 & 3.00 \\
\hline .00 & 0.50 & 0.51 & 0.52 & 0.52 & 0.53 & 0.54 & 0.54 & 0.55 & 0.56 & 0.57 & 0.58 & 0.59 & 0.60 & 0.61 & 0.63 & 0.64 & 0.65 & 0.67 \\
\hline 0.05 & 0.50 & 0.51 & 0.52 & 0.52 & 0.53 & 0.54 & 0.54 & 0.55 & 0.56 & 0.57 & 0.58 & 0.59 & 0.60 & 0.61 & 0.63 & 0.64 & 0.65 & 0.67 \\
\hline .10 & 0.50 & 0.51 & 0.52 & 0.52 & 0.53 & 0.54 & 0.54 & 0.55 & 0.56 & 0.57 & 0.58 & 0.59 & 0.60 & 0.61 & 0.63 & 0.64 & 0.66 & 0.67 \\
\hline 0.15 & 0.50 & 0.51 & 0.52 & 0.52 & 0.53 & 0.54 & 0.54 & 0.55 & 0.56 & 0.57 & 0.58 & 0.59 & 0.60 & 0.61 & 0.63 & 0.64 & 0.66 & 0.67 \\
\hline 0.20 & 0.50 & 0.51 & 0.52 & 0.52 & 0.53 & 0.54 & 0.54 & 0.55 & 0.57 & 0.58 & 0.59 & 0.59 & 0.60 & 0.61 & 0.63 & 0.64 & 0.66 & 0.67 \\
\hline 0.25 & 0.50 & 0.51 & 0.52 & 0.52 & 0.53 & 0.54 & 0.54 & 0.56 & 0.57 & 0.58 & 0.59 & 0.60 & 0.60 & 0.61 & 0.63 & 0.65 & 0.66 & 0.67 \\
\hline 0.30 & 0.50 & 0.51 & 0.52 & 0.52 & 0.53 & 0.54 & 0.54 & 0.56 & 0.57 & 0.58 & 0.59 & 0.60 & 0.60 & 0.61 & 0.63 & 0.65 & 0.66 & 0.67 \\
\hline 0.35 & 0.50 & 0.51 & 0.52 & 0.52 & 0.53 & 0.54 & 0.54 & 0.56 & 0.57 & 0.58 & 0.59 & 0.60 & 0.61 & 0.61 & 0.63 & 0.65 & 0.66 & 0.68 \\
\hline 0.40 & 0.50 & 0.51 & 0.52 & 0.52 & 0.53 & 0.54 & 0.55 & 0.56 & 0.57 & 0.58 & 0.59 & 0.60 & 0.61 & 0.62 & 0.64 & 0.65 & 0.67 & 0.68 \\
\hline 0.45 & 0.50 & 0.51 & 0.52 & 0.52 & 0.53 & 0.54 & 0.55 & 0.56 & 0.57 & 0.58 & 0.59 & 0.60 & 0.61 & 0.62 & 0.64 & 0.66 & 0.67 & 0.68 \\
\hline 0.50 & 0.50 & 0.51 & 0.52 & 0.53 & 0.53 & 0.54 & 0.55 & 0.56 & 0.57 & 0.59 & 0.60 & 0.61 & 0.61 & 0.62 & 0.64 & 0.66 & 0.67 & 0.69 \\
\hline .55 & 0.50 & 0.51 & 0.52 & 0.53 & 0.53 & 0.54 & 0.55 & 0.56 & 0.58 & 0.59 & 0.60 & 0.61 & 0.62 & 0.63 & 0.65 & 0.66 & 0.68 & 0.69 \\
\hline 0.60 & 0.50 & 0.51 & 0.52 & 0.53 & 0.54 & 0.54 & 0.55 & 0.57 & 0.58 & 0.59 & 0.60 & 0.61 & 0.62 & 0.63 & 0.65 & 0.67 & 0.69 & 0.70 \\
\hline 0.65 & 0.50 & 0.51 & 0.52 & 0.53 & 0.54 & 0.55 & 0.55 & 0.57 & 0.58 & 0.60 & 0.61 & 0.62 & 0.63 & 0.64 & 0.66 & 0.68 & 0.69 & 0.71 \\
\hline 0.70 & 0.50 & 0.51 & 0.52 & 0.53 & 0.54 & 0.55 & 0.56 & 0.57 & 0.59 & 0.60 & 0.61 & 0.63 & 0.64 & 0.65 & 0.67 & 0.69 & 0.70 & 0.72 \\
\hline 0.75 & 0.50 & 0.51 & 0.52 & 0.53 & 0.54 & 0.55 & 0.56 & 0.58 & 0.60 & 0.61 & 0.62 & 0.63 & 0.65 & 0.66 & 0.68 & 0.70 & 0.71 & 0.73 \\
\hline 0.80 & 0.50 & 0.51 & 0.53 & 0.54 & 0.55 & 0.56 & 0.57 & 0.59 & 0.60 & 0.62 & 0.63 & 0.65 & 0.66 & 0.67 & 0.69 & 0.71 & 0.73 & 0.74 \\
\hline 0.85 & 0.50 & 0.51 & 0.53 & 0.54 & 0.55 & 0.57 & 0.58 & 0.60 & 0.62 & 0.63 & 0.65 & 0.66 & 0.68 & 0.69 & 0.71 & 0.73 & 0.75 & 0.76 \\
\hline 0.90 & 0.50 & 0.52 & 0.53 & 0.55 & 0.57 & 0.58 & 0.59 & 0.62 & 0.64 & 0.66 & 0.68 & 0.69 & 0.70 & 0.72 & 0.74 & 0.76 & 0.78 & 0.79 \\
\hline 0.95 & 0.50 & 0.52 & 0.55 & 0.57 & 0.59 & 0.61 & 0.63 & 0.66 & 0.68 & 0.71 & 0.73 & 0.74 & 0.76 & 0.77 & 0.80 & 0.81 & 0.83 & 0.84 \\
\hline
\end{tabular}


factor 0.18 moet worden gewogen. Uit tabel 1 kunnen we afleiden dat de verbetering van de voorspelkwaliteit, gerelateerd aan die van het management, slechts $3 \%$ bedraagt.

Tabel 4. Gegevens betreffende omzetvoorspelfouten.

\begin{tabular}{|c|c|c|c|c|c|c|}
\hline & \multicolumn{3}{|c|}{ fractie tegengestelde voorspelfouten } & \multicolumn{3}{|c|}{ fractie kleinere voorspelfouten } \\
\hline & $\begin{array}{l}\text { Manage- } \\
\text { ment }\end{array}$ & $\begin{array}{l}\text { Elton \& } \\
\text { Gruber }\end{array}$ & $\begin{array}{l}\text { Identieke } \\
\text { Verandering }\end{array}$ & $\begin{array}{l}\text { Manage- } \\
\text { ment }\end{array}$ & $\begin{array}{l}\text { Elton \& } \\
\text { Gruber }\end{array}$ & $\begin{array}{l}\text { Identieke } \\
\text { Verandering }\end{array}$ \\
\hline \multirow{5}{*}{$\begin{array}{l}\text { Elton \& } \\
\text { Gruber } \\
\text { Identieke } \\
\text { Verandering } \\
\text { Analisten }\end{array}$} & .273 & & & .529 & & \\
\hline & .273 & .172 & & .588 & .536 & \\
\hline & .242 & .324 & .206 & .594 & .529 & .529 \\
\hline & \multicolumn{3}{|c|}{ geschatte correlatie } & \multicolumn{3}{|c|}{$\begin{array}{l}\text { geschatte verhouding verwachte } \\
\text { kwadratische voorspelfout }\end{array}$} \\
\hline & $\begin{array}{l}\text { Manage- } \\
\text { ment }\end{array}$ & $\begin{array}{l}\text { Elton \& } \\
\text { Gruber }\end{array}$ & $\begin{array}{l}\text { Identieke } \\
\text { Verandering }\end{array}$ & $\begin{array}{l}\text { Manage- } \\
\text { ment }\end{array}$ & $\begin{array}{l}\text { Elton \& } \\
\text { Gruber }\end{array}$ & $\begin{array}{l}\text { Identieke } \\
\text { Verandering }\end{array}$ \\
\hline $\begin{array}{l}\text { Elton \& } \\
\text { Gruber } \\
\text { Identieke }\end{array}$ & .65 & & & 1.15 & & \\
\hline Verandering & .65 & .85 & & 1.5 & 1.1 & \\
\hline Analisten & .70 & .50 & .80 & 1.5 & 1.15 & 1.1 \\
\hline
\end{tabular}

We mogen hieruit concluderen dat de informatieve waarde van de analistenvoorspellingen slechts gering is als we eenmaal over een managementprognose kunnen beschikken.

Een volgend aspect dat we uit tabel 4 naar voren willen halen betreft de hoge geschatte correlatie tussen de analistenvoorspellingen en de voorspellingen verkregen door het model in identieke veranderingen. Deze hoge correlatie impliceert dat de methode waarop analisten tot een voorspelling komen vrijwel equivalent is aan het doortrekken van de verandering in het afgelopen jaar. De correlatie tussen de voorspellingen van het Elton \& Gruber-model en het model in identieke veranderingen volgt uit het feit dat het laatste model een bijzonder geval is van het eerste.

We merken op dat analisten voor dit gegevensmateriaal hun voorspelnauwkeurigheid kunnen vergroten door de initiële voorspellingen te combineren met het Elton \& Gruber-model.

Op grond van tabel 1 signaleren we dat de nauwkeurigheid van analisten met $30 \%$ toe kan nemen door te combineren met het Elton \& Grubermodel. Combineren met het model in identieke veranderingen levert minder winst op, nl. $14 \%$. Het management kan haar nauwkeurigheid minder vergroten door te combineren met de Elton \& Gruber voorspelling. De relatieve verbetering van de verwachte absolute voorspelfout zal slechts $6 \%$ bedragen.

\subsection{Optimale winstvoorspellingen}

Voor 38 ondernemingen beschikken we zowel over een management-als 
een analistenvoorspelling van de winst. Deze voorspellingen hebben we nog aangevuld met een tijdreeksvoorspelling, namelijk die van het pure random walk-model. De voorspelling van de winst is gelijk aan de gerealiseerde winst in het afgelopen jaar. Van de tijdreeksmodellen die voor het voorspellen van de winst zijn gebruikt, bleek het random walk-model optimale voorspeleigenschappen te hebben. We verwijzen hiervoor naar Schreuder en Klaassen (1982a, hfst. 5) en Kodde en Schreuder (1983). Evenals voor de omzet presenteren we ook voor de winst de beide fracties en de schattingen van correlaties en variantieverhouding.

Tabel 5. Gegevens betreffende winstvoorspelfouten.

\begin{tabular}{|c|c|c|c|c|}
\hline & \multicolumn{2}{|c|}{$\begin{array}{c}\text { fractie tegengestelde voorspel- } \\
\text { fouten }\end{array}$} & \multicolumn{2}{|c|}{ fractie kleinere voorspelfouten } \\
\hline & Management & Analisten & Management & Analisten \\
\hline Analisten & .184 & & .526 & \\
\hline \multirow[t]{3}{*}{ Random walk } & .184 & .211 & .526 & .526 \\
\hline & \multicolumn{2}{|c|}{ geschatte correlatie } & \multicolumn{2}{|c|}{$\begin{array}{l}\text { geschatte verhouding verwachte } \\
\text { kwadratische voorspelfout }\end{array}$} \\
\hline & Management & Analisten & Management & Analisten \\
\hline Analisten & .85 & & 1.10 & \\
\hline Random walk & .85 & .80 & 1.10 & 1.10 \\
\hline
\end{tabular}

We vinden dat de winstvoorspellingen van managers nauwkeuriger zijn dan die van analisten, welke op hun beurt weer nauwkeuriger zijn dan de voorspellingen verkregen met het pure random walk-model. De verschillen in voorspelkwaliteit zijn echter allerminst significant. De hoge correlaties tussen management en analistenvoorspellingen enerzijds en het pure random walk-model anderzijds wijzen op het feit dat toekomstverwachtingen van managers en analisten in hoge mate door de huidige gebeurtenissen worden bepaald. Daarnaast impliceert de hoge correlatie dat alle voorspellers dezelfde gebeurtenissen niet hebben voorzien. Het twee aan twee combineren van voorspellingen verbetert de voorspelkwaliteit met maximaal 6\%. Deze marginale verbeteringen impliceren ook dat het combineren van zowel de management-, analisten-als random walk-voorspelling slechts een kleine verbetering in de voorspelkwaliteit op zal leveren.

\section{Samenvatting en conclusies}

In dit artikel hebben we een methode ontwikkeld om de voorspelkwaliteit te verbeteren door het combineren van verschillende voorspellingen. De realiseerbare voorspelkwaliteit is hoger naarmate in de verschillende voorspellingen niet dezelfde ontwikkelingen zijn meegenomen. De ontwikkelde methode is toegepast op voorspellingen van omzetten en winsten van Nederlandse ondernemingen voor 1980 . Naast het verbeteren van de voorspelkwaliteit biedt de methode middels het analyseren van correlaties de mogelijkheid om vast te stellen op welke wijze bepaalde voorspellingen tot 
stand komen. Voor de omzet vinden we dat de managementvoorspellingen niet te verbeteren zijn door te combineren met analistenvoorspellingen. Verder signaleerden we dat de methode waarop analisten tot een omzetvoorspelling komen grote overeenkomst vertoont met een voorspelling die op de groei in het afgelopen jaar is gebaseerd. Analisten kunnen hun omzetvoorspelling verbeteren door rekening te houden met voorspellingen die door het Elton \& Gruber-model worden gegenereerd.

Voor de winst zijn de correlaties tussen de voorspelfouten van management, analisten en random walk-model zeer hoog, hetgeen wil zeggen dat historische winstontwikkelingen slechts van geringe betekenis zijn bij het bepalen van een voorspelling. Voor dit gegevensmateriaal valt de winstvoorspelling slechts in zeer geringe mate te verbeteren door te combineren. Het geheel overziende moeten we concluderen dat de voorspelkwaliteit slechts ingeringe mate wordt verbeterd door het combineren van omzet- en winstvoorspellingen.

\section{Mathematische appendix}

In deze appendix geven we aan hoe meerdere voorspellingen tot een optimale voorspelling kunnen worden gecombineerd. Dit betreft een uitbreiding van de methode in paragraaf 3 . Daarnaast onderbouwen we de schattingsprocedure van $\rho$ en $\sigma_{2}{ }^{2} / \sigma_{1}{ }^{2}$ uit paragraaf 4.2 .

\section{Combineren van meerdere voorspellingen}

Stel we beschikken over $\mathrm{n}$ voorspellingen. De verwachting van de voorspelfout is 0 . We geven de variantie-covariantiematrix van de voorspelfouten, $\mathrm{u}$, aan met $\mathrm{V}$. De optimale voorspelling wordt gevonden door de vector van gewichten te kiezen zodanig dat $\mathrm{E}\left(\delta^{\prime} \mathrm{u}\right)^{2}$ minimaal is en $\mathrm{i}^{\prime} \delta=1$, waarbij $\mathrm{i}$ een vector van dimensie $n$ gevuld met enen voorstelt. Deze gewichten worden gevonden door het volgende Lagrange-multiplierprobleem op te lossen: $\min \mathrm{Q}=\delta^{\prime} \mathrm{V} \delta-\lambda\left(\mathrm{i}^{\prime} \delta-1\right)$.

De oplossing wordt verkregen uit het volgende stelsel eerste-orde vergelijkingen: $\partial \mathrm{Q} / \partial \delta=2 \mathrm{~V} \delta-\lambda \mathrm{i}=0 \quad \partial \mathrm{Q} / \partial \lambda=\mathrm{i}^{\prime} \delta-1=0$,

waaruit volgt dat de volgende keuze van de gewichten een optimale voorspelling levert $\delta=\left[\mathrm{V}^{-1} \mathbf{i}\right] /\left[\mathrm{i}^{\prime} \mathrm{V}^{-1} \mathbf{i}\right]$.

De verwachte kwadratische voorspelfout is dan $\sigma_{\min }^{2}=1 /\left[\mathrm{i}^{\prime} \mathrm{V}^{-1} \mathbf{i}\right]$.

Op grond van formule (3) volgt dat de voorspelkwaliteit van een gecombineerde voorspelling niet toeneemt indien $\rho=\sigma_{1} / \sigma_{2}$.

Met behulp van deze eigenschap zullen we laten zien dat de voorspelkwaliteit niet wordt vergroot door meerdere keren dezelfde voorspelling te combineren. Kies een willekeurige vector van gewichten, $\gamma$, waarvoor geldt $i^{\prime} \gamma=1$. De verwachte kwadratische voorspelfout is dan gelijk aan $\gamma^{\prime} V_{\gamma}$, 
terwijl de covariantie tussen de twee gecombineerde voorspellingen wordt gegeven door $\delta^{\prime} \mathrm{V} \gamma$.

Zodat de correlatie gelijk is aan $\rho=\left[\delta^{\prime} \mathrm{V} \gamma /\left(\mathrm{i}^{\prime} \mathrm{V}^{-1} \mathbf{i}\right)\right] / \sqrt{ }\left(\gamma^{\prime} \mathrm{V} \gamma\right)$.

Om het gestelde aan te tonen substitueren we de vector van gewichten, zodat $\rho=\left[\mathrm{i}^{\prime} \mathrm{V}^{-1} \mathrm{~V} \gamma\right] /\left[\mathcal{V}\left(\gamma^{\prime} \mathrm{V} \gamma\right) /\left(\mathrm{i}^{\prime} \mathrm{V}^{-1} \mathrm{i}\right)\right]=\sigma_{\min } / \sigma \gamma$.

\section{Het schatten van correlatie en variantieverhouding}

De in dit artikel beschreven methoden kunnen toegepast worden als er een schatting van de correlatie en de variantieverhouding van de verschillende voorspellingen beschikbaar is. In dit deel van de appendix zullen we mathematisch uiteenzetten hoe deze grootheden verkregen kunnen worden. Omdat correlatie en variantieverhouding niet op de gebruikelijke wijze direct kunnen worden berekend, een soortgelijk probleem komt naar voren in Schreuder en Klaassen (1982a en 1982b) en Kodde en Schreuder (1983), zullen we een methode ontwikkelen waarmee we wel betrouwbare schattingen kunnen verkrijgen. Hierbij hanteren we de veronderstelling dat de correlatie en verhouding van de verwachte kwadratische voorspelfout van management- en analistenvoorspelling van bedrijf tot bedrijf gelijk zijn. We nemen aan dat de voorspelfouten $\mathrm{u}_{1}$ en $\mathrm{u}_{2}$, welke respectievelijk behoren bij voorspellingen $f_{1}$ en $f_{2}$, normaal zijn verdeeld met verwachting nu1 en

variantie-covariantie matrix gelijk aan

$$
\left[\begin{array}{cc}
1 & \rho \sqrt{ } y \\
\rho \sqrt{ } y & 1
\end{array}\right] \text {, }
$$

waarbij y staat voor de verhouding van de variantie $\sigma_{2}{ }^{2} / \sigma_{1}{ }^{2}$.

Op basis van ons empirische materiaal kunnen we nu de fractie berekenen dat de voorspelfouten $u_{1}$ en $u_{2}$ een tegengesteld teken hebben. Dit wil zeggen dat een van de voorspellingen te hoog is geweest en de ander te laag. We zullen laten zien hoe op basis hiervan een schatting van de correlatie kan worden verkregen. We berekenen daartoe

$$
\begin{aligned}
& \mathrm{P}\left(\mathrm{u}_{1}<0 \mid \mathrm{u}_{2}>0\right)+\mathrm{P}\left(\mathrm{u}_{1}>0 \mid \mathrm{u}_{2}<0\right)= \\
& 2 \int_{0} \int_{\infty}^{0} \mathrm{f}_{\mathrm{u}_{1} \mid \mathrm{u}_{2}}\left(\mathrm{u}_{1} \mid \mathrm{u}_{2}\right) \mathrm{du}_{1} \mathrm{f}_{\mathrm{u}_{2}}\left(\mathrm{u}_{2}\right) \mathrm{du} \mathrm{u}_{2}= \\
& 2 /(\sqrt{ } 2 \pi \mathrm{y}) \int_{0}^{\pi} \Phi\left[\left(-\rho \mathrm{u}_{2} / \sqrt{ } \mathrm{y}\right) / \sqrt{ }\left(1-\rho^{2}\right)\right] \exp \left(-\mathrm{u}_{2}^{2} / 2 \mathrm{y}\right) \mathrm{du}_{2}= \\
& 2 /(\sqrt{ } 2 \pi) \int_{0}^{\infty} \Phi\left[-\rho \mathbf{x} / \sqrt{ }\left(1-\rho^{2}\right)\right] \exp \left(-\mathrm{x}^{2} / 2\right) \mathrm{d} \mathbf{x},
\end{aligned}
$$

waarbij $\Phi(\mathrm{x})$ de cumulatieve standaard normale verdeling in het punt $\mathrm{x}$ weergeeft. De $\mathrm{f}_{\mathrm{u}_{9},}$ en $\mathrm{f}_{\mathrm{u}_{1} \mid \mathrm{u}_{9}}$ geven respectievelijk de dichtheidsfuncties van de marginale verdeling van $u_{2}$ en conditionele verdeling van $u_{1}$ gegeven $u_{2}$ weer. De formule kan door numerieke integratie als functie van enkel $\rho$ worden bepaald. In tabel 2 wordt bovenstaande expressie voor een reeks van positieve $\rho$-waarden gegeven. Als de fractie tegengestelde voorspelfouten groter is dan $50 \%$, dan kan de bijbehorende negatieve waarde van de correlatiecoëfficiënt uit tabel 2 worden bepaald door de waarde van $\rho$, die 
behoort bij 1-fractie tegengestelde voorspelfouten van een min-teken te voorzien. Dit vanwege het feit dat geldt $\Phi(\mathrm{x})=1-\Phi(-\mathrm{x})$.

Het empirische materiaal biedt ook de mogelijkheid om de fractie van het aantal voorspellingen waar de ene voorspelfout in absolute waarde kleiner is dan de andere te bepalen. Hierdoor kunnen we, nadat we een schatting voor $\rho$ hebben bepaald, de variantie-verhouding schatten. Mathematisch kan de verwachte fractie weergegeven worden door

$$
\begin{aligned}
& \mathrm{P}\left(\left|\mathrm{u}_{1}\right|<\left|\mathrm{u}_{2}\right|\right)= \\
& \mathrm{P}\left(\left|\mathrm{u}_{1}\right|<\mathrm{u}_{2} \mid \mathrm{u}_{2}>0\right)+\mathrm{P}\left(\left|\mathrm{u}_{1}\right|<-\mathrm{u}_{2} \mid \mathrm{u}_{2}<0\right)= \\
& 2 \int_{n}^{\rho} \int_{-\mathrm{u}_{2}}^{\mathrm{u}_{2}} \mathrm{f}_{\mathrm{u}_{1} \mid \mathrm{u}_{2}}\left(\mathrm{u}_{1} \mid \mathrm{u}_{2}\right) \mathrm{du}_{1} \mathrm{f}_{\mathrm{u}_{2}}\left(\mathrm{u}_{2}\right) \mathrm{du}_{2}= \\
& 2 /(\sqrt{ } 2 \pi \mathrm{y}) \int_{0}^{+}\left\{\Phi\left[\mathrm{u}_{2}(1-\rho / \sqrt{ }) / \sqrt{ }\left(1-\rho^{2}\right)\right]-\Phi\left[\mathrm{u}_{2}(-1-\rho / \sqrt{ } \mathrm{y}) / \sqrt{ }\left(1-\rho^{2}\right)\right]\right\} \\
& \exp \left(-\mathrm{u}_{2}{ }^{2} / 2 \mathrm{y}\right) \mathrm{du}_{2}
\end{aligned}
$$

welke formule ook weer door numerieke integratie kan worden bepaald. In tabel 3 worden deze kansen voor verschillende waarden van $\rho$ en y gepresenteerd. De tabel is alleen voor positieve $\rho$ gegeven, omdat een negatieve waarde van $\rho$ een identieke waarde geeft als de bijbehorende positieve waarde, namelijk er geldt

$$
\begin{aligned}
& \Phi(1-\rho \mathbf{x})-\Phi(-1-\rho \mathbf{x})=1-\Phi(-1+\rho \mathbf{x})-1+\Phi(1+\rho \mathbf{x})= \\
& \Phi(1+\rho \mathbf{x})-\Phi(-1+\rho \mathbf{x}) .
\end{aligned}
$$

\section{Noten}

* De auteur dankt $H$. Schreuder en de redactie van het MAB voor hun reacties op een eerdere versie van dit artikel.

\section{Literatuur}

Bates, J. M. en Granger, C. W. J., 1969, The combination of forecasts, Operations Research Quarterly.

Van Doorn, J. W. M. en Van Vught, F. A., 1982, Toekomstonderzoek: een tour d'horizon d'un tour de force, Maandblad voor Accountancy en Bedrijfshuishoudkunde, juni/juli.

Elton, E. J. en Gruber, M. J., 1972, Earnings estimates and the accuracy of expectational data, Management Science.

Granger, C. W. J., en Newbold, P., 1977, Forecasting economic time series, New York, Academic Press.

Jaggi, B., 1980, Further evidence on the accuracy of management forecasts vis-a-vis analysts' forecasts, Accounting Review, january.

Kodde, D. A. en Palm, F. C., 1982, Het genereren van voorspellingen van omzet en nettowinst, Maandblad voor Accountancy en Bedrijfshuishoudkunde, juni/juli.

Kodde, D. A. en Schreuder, H., 1983, Forecasting corporate revenue and profit: Time-series models versus management and analysts, Researchmemorandum, Vrije Universiteit. Te verschijnen in Journal of Business Finance and Accounting.

Leeflang, P. S. H., 1982, Planning en forecasting in marketing, Maandblad voor Accountancy en Bedrijfshuishoudkunde, juni/juli.

Ruland, W., 1978, The accuracy of forecasts by management and by financial analysts, Accounting Review, april.

Schreuder, H. en Klaassen, J., m.m.v. D. A. Kodde, 1982a, De voorspelbaarheid van omzetten en winsten, Leiden, Stenfert Kroese.

Schreuder, H. en Klaassen, J., 1982b, Confidential revenue and profit forecasts by management and financial analysts, evidence from the Netherlands, Researchmemorandum, Vrije Universiteit. Te verschijnen in de Accounting Review. 